\title{
ARRANJO DE SEMEADURA PARA CULTIVARES DECUMBENTES PRECOCES DE AMENDOIM
}

$\underline{\text { Jair Heuert }}^{1}$, Allan Carlos Alves de Souza ${ }^{9}$; Bruno Nunes Oliveira ${ }^{7}$ Cristiano Zerbato ${ }^{5}$; Lucas

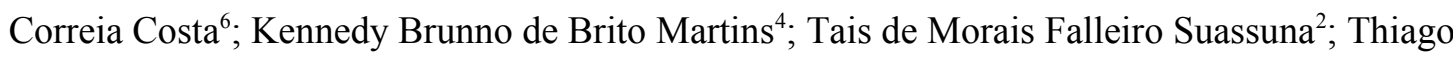
Cândido do Nascimento Ribeiro ${ }^{8}$; Rodolfo Pires Ribeiro ${ }^{3}$; Valdinei Sofiatti ${ }^{2}$.

${ }^{1}$ Engenheiro Agrônomo e Técnico Agrícola na Embrapa jair.heuert@embrapa.br (Apresentador do Trabalho), ${ }^{2}$ Pesquisadores da Embrapa Algodão, tais.suassuna@embrapa.br e valdinei.softiatti@embrapa.br, ${ }^{3}$ Engenheiro Agrônomo da Beatrice Peanuts, ${ }^{4}$ Acadêmico de biologia da Faculdade Araguaia, ${ }^{5}$ Professor UNESP Jaboticabal, ${ }^{6}$ Estudante do Colégio Estadual Padre Alexandre de Morais - Santo Antônio de Goiás-GO, ${ }^{7}$ Acadêmico de Agronomia da FAFICH Goiatuba; ${ }^{8}$ Acadêmico de biologia da UEG, ${ }^{9}$ Doutorando em fitopatologia na UFL.

RESUMO: O amendoim é uma cultura importante para a diversificação dos sistemas de produção agrícola no Brasil. O estado de São Paulo é o maior produtor, onde o amendoim é cultivado principalmente em áreas de renovação de canaviais. Cultivares "Runner" precoces foram desenvolvidas recentemente, demandando estudos sobre espaçamentos e arranjos de semeadura mais adequados para estes genótipos de crescimento mais determinado que as cultivares "Runner" tradicionais. A linhagem 2013-413 OL apresenta crescimento mais determinado e foi utilizada em um ensaio para avaliar arranjos de semeadura. O ensaio foi instalado na área experimental da Embrapa Arroz e Feijão em Santo Antônio de Goiás-GO, em blocos casualizados com quatro repetições e três tratamentos: T1: $90 \mathrm{~cm}$; T2: $73 \mathrm{~cm}$ x $17 \mathrm{~cm}$ e T3: de $75 \mathrm{~cm}$. Cada parcela foi composta por quatro linhas, somente as duas linhas centrais foram avaliadas. Os resultados mostraram que no espaçamento $90 \mathrm{~cm}$ a produtividade foi obtida foi de $3564,81 \mathrm{~kg} \mathrm{ha}^{-1}$, no espaçamento de $73 \mathrm{~cm} \mathrm{x} 17 \mathrm{~cm}$ obteve-se $3958,33 \mathrm{~kg} \mathrm{ha}^{-1}$ e no espaçamento de $75 \mathrm{~cm}$ obteve-se $4511,11 \mathrm{~kg} \mathrm{ha}^{-1}$.

Palavra chaves: Arachis hypogaea L., configuração de semeadura, população de plantas, espaçamento entre fileiras.

\section{INTRODUÇÃO}

O cultivo do amendoim tipo "Runner" é recente no Brasil (GODOY, 2001) e o arranjo de plantio adotado é baseado naquele utilizado nos Estados Unidos, com fileiras simples espaçadas de $90 \mathrm{~cm}$ e fileiras duplas espaçadas de $73 \mathrm{~cm} \times 17 \mathrm{~cm}$. Portanto, acredita-se que pode haver um modelo mais apropriado para as condições brasileiras. Há questionamentos por parte de alguns agricultores sobre a redução do espaçamento entre fileiras e uma discussão sobre diferentes arranjos espaciais de plantas de amendoim mais adequados às cultivares brasileiras (FERNANDES 2004; ZERBATO 2014).

$\mathrm{Na}$ última década, pouco foi estudado sobre este assunto, visando dar subsídios aos produtores de amendoim no país, sobretudo com novas cultivares (TASSO JUNIOR et al. 2004). A importância de novos trabalhos sobre arranjos espaciais de plantas de amendoim é 
percebida por alguns aspectos que vêm impactando essa cultura no Brasil nos últimos anos, como: mudanças nas características morfofisiológicas de algumas novas cultivares de amendoim, principalmente precocidade e produção mais concentrada próxima da haste principal; o aumento da expectativa de produtividade de grãos; custo elevado das sementes (ROMANINI JUNIOR, 2007; MARTINS, 2010 e GODOY et al., 2005).

Em cultivares de porte ereto verificou-se que a redução no espaçamento, tem proporcionado maiores produtividades (NAKAGAWA et al., 1994; SILVA e BELTRÃO, 2000; BELLETTINI e ENDO, 2001; GONÇALVES et al., 2004). DIAS (2007), avaliando a cultivar 'Runner IAC 886' observou que a redução de $90 \mathrm{~cm}$ para $80 \mathrm{~cm}$ resultou em maior produtividade. Em outro estudo, avaliando redução de espaçamentos na região Nordeste, OLIVEIRA et al. (2010) relatam aumento de produtividade quando o espaçamento foi reduzido de $90 \mathrm{~cm}$ para $50 \mathrm{~cm}$ com a cultivar 'Runner IAC 886'; a cultivar 'IAC Caiapó', de crescimento indeterminado, não apresentou o mesmo resultado.

\section{MATERIAIS E MÉTODOS}

O experimento foi instalado na safra 2016/17, na área experimental da Embrapa no município de Santo Antônio de Goiás-GO. A linhagem 2013-413 OL, de crescimento determinado, foi semeada manualmente no dia 22 de dezembro de 2016. A adubação de base foi realizada com adubo formulado 0-20-20 de NPK numa dosagem de $250 \mathrm{Kg} \mathrm{ha}^{-1}$ e os demais tratos culturais seguiram as recomendações para a cultura, resultando em desenvolvimento adequado das plantas. O delineamento experimental utilizado foi o de blocos casualizados com quatro repetições, as parcelas eram compostas por quatro linhas de três metros de comprimento. Os tratamentos foram os seguintes: T1) amendoim semeado em fileiras simples, $90 \mathrm{~cm}$ entre linhas e 20 sementes por metro linear, com uma área útil 5,4 $\mathrm{m}^{2}$; T2) amendoim semeado em fileiras duplas, com duas linhas distanciadas a $17 \mathrm{~cm}$, mantendo-se a distância de $73 \mathrm{~cm}$ entre as linhas, utilizando 20 sementes por metro linear divididas nas linhas com área útil de parcela de $5,4 \mathrm{~m}^{2}$ (ROMANINI JUNIOR, 2007) e T3) amendoim semeado em fileiras simples com espaçamento entre fileiras de $75 \mathrm{~cm}$, utilizando 12 sementes por metro linear ocupando uma área de parcela útil de $4,5 \mathrm{~m}^{2}$.

Para inversão das parcelas foi usado um arrancador de duas linhas da marca MIAC, modelo C200. O amendoim foi arrancado e invertido aos 135 dias após a semeadura e após o período de secagem no campo, foram colhidas às duas linhas centrais de cada parcela para determinação da produtividade. Para analise estatística foi realizado o teste Turkey $(p \leq 0,1)$ com uso do software SPSS versão 21. 


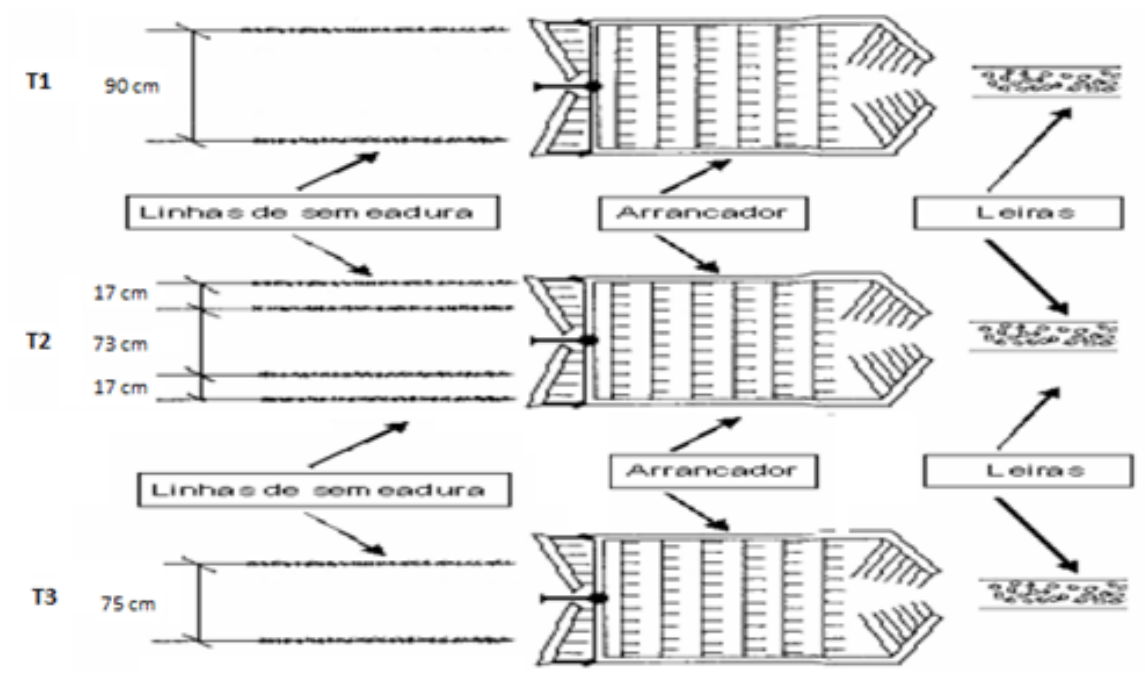

Figura 1. Esquema ilustrativo das linhas de semeadura dos arranjos de semeadura em fileiras simples $(\mathrm{T} 1-90 \mathrm{~cm} ; \mathrm{T} 3-75 \mathrm{~cm})$ e duplas $(\mathrm{T} 2-73 \mathrm{~cm} \times 17 \mathrm{~cm})$.

\section{RESULTADOS E DISCUSSÕES}

Comparando os resultados de produtividade de cada tratamento, observamos que esta linhagem se adapta bem ao sistema de linha dupla, onde produziu $11,04 \%$ a mais em comparação ao arranjo com espaçamento de $90 \mathrm{~cm}$ (T1). ROMANINI JUNIOR (2007) observou que a produtividade de vagens da cultivar 'Runner IAC 886', em arranjo de linhas duplas obteve produtividade de $11,1 \%$ superior em comparação com o espaçamento linha simples. Quando se utilizou o arranjo de plantio em fileiras simples com espaçamento entre as mesmas de $75 \mathrm{~cm}$ (T3), verificou-se que a produtividade foi ainda maior do que aquela utilizada no arranjo de fileiras duplas. Provavelmente, neste tratamento houve uma melhor otimização da área, uma vez que, neste arranjo de semeadura utilizou-se menor população de plantas na linha de semeadura, porém com fileiras menos espaçadas entre si, gerando um aumento de produtividade de 26,55\% em relação ao espaçamento entre fileiras de $90 \mathrm{~cm}$ (WALKER et al., 2010). Entretanto, verificou-se que neste tratamento $(75 \mathrm{~cm})$ houve dificuldade na inversão com o arrancador.

Tabela 1. Produtividade de amendoim em diferentes espaçamentos de cultivo.

\begin{tabular}{ccc}
\hline Espaçamento $(\mathrm{cm})$ & População Plantas ha & Produtividade $\left(\mathrm{kg} \mathrm{ha}^{-1}\right)$ \\
\hline 90 & $137.037 \mathrm{~b}$ & $3564,81 \mathrm{~b}$ \\
$73+17$ & $133.333 \mathrm{~b}$ & $3958,33 \mathrm{~b}$ \\
75 & $116.111 \mathrm{a}$ & $4511,11 \mathrm{a}$ \\
\hline C.V. $(\%)$ & 6.95 & 18,3 \\
\hline F. & $3.53^{*}$ & $3.74^{*}$ \\
\hline Média & $128.827,14$ & 4011.42 \\
\hline
\end{tabular}


Letras minúsculas nas colunas apresentam diferença estatística pelo Teste de Tukey $(\mathrm{p} \leq 0,1)$.

$*=$ significativo a $5 \%$ de probabilidade de erro

A linhagem 2013-413 OL se adapta bem aos diferentes sistemas adotados no Brasil para o cultivo de amendoim. Verificou-se também que é possível semeá-la em espaçamento entre fileiras menor do que $90 \mathrm{~cm}$, provavelmente devido ao seu crescimento mais determinado e produção de vagens mais próxima da haste central da planta. A redução no espaçamento é viável desde que haja variedades adequadas e disponibilidade de arrancadores/invertedores ajustados para um espaçamento menor do que $90 \mathrm{~cm}$.

Mais estudos com genótipos de amendoim decumbentes precoces poderão fornecer informações importantes sobre mudanças nas características morfofisiológicas, auxiliando tanto no manejo cultural quanto no desenvolvimento de novas cultivares de amendoim "Runner" precoces.

\section{CONCLUSÕES}

A linhagem 2013-413 OL apresentou bom desempenho tanto nos arranjos de fileira simples tradicional $(90 \mathrm{~cm})$, quanto reduzido $(75 \mathrm{~cm})$, quanto em fileiras duplas $(73 \times 17 \mathrm{~cm})$.

\section{REFERENCIAS BIBLIOGRÁFICAS}

BELlETTINI, N. M. T.; ENDO, R. M. Comportamento do amendoim "das águas", Arachis hypoaea L., sob diferentes espaçamentos e densidades de semeadura. Acta Scientiarum, Maringá, v. 23, n. 5, p. 1249-1256, 2001.

BULGARELLI, E.M.B. Caracterização de variedades de amendoim cultivadas em diferentes populações - Dissertação (mestrado) - Universidade Estadual Paulista, Faculdade de Ciências Agrárias e Veterinárias, Jaboticabal, 2008.

DIAS, Tomás Carneiro de Souza. Efeito do espaçamento na interferência das plantas daninhas na cultura do amendoim. 2007. iii, $44 \mathrm{f}$. Dissertação (mestrado) - Universidade Estadual Paulista, Faculdade de Ciências Agrárias e Veterinárias, 2007. Disponível em: $<$ http:/hdl.handle.net/11449/96907>.

FERNANDES, R. Programação de colheita de amendoim. Arranquio e Colheita (bateção). In Encontro sobre a cultura do amendoim, 1, 2004, Jaboticabal. Palestras... Jaboticabal: FUNEP, 2004 (CD-ROOM)

GONÇAlVES, J. A.; PEIXOTO, C. P.; LEDO, C. A. S.; PEIXOTO, M. F. S. P.; SAMPAIO, H. S. V.; SAMPAIO, L. S. V.; ALMEIDA, N. S. Componentes de produção e rendimento de amendoim em diferentes arranjos espaciais no Recôncavo Baiano. Revista Brasileira de Oleaginosas e Fibrosas. Campina Grande, v. 8, n. 2/3, p. 801-812, 2004.

GODOY, I.J. Problemas e perspectivas do melhoramento genético do amendoim no Brasil. In: SIMPÓSIO DE RECURSOS GENÉTICOS PARA A AMÉRICA LATINA E CARIBE, 3. 
Londrina, 2001. Anais... Londrina: IAPAR,2001. p. 43-46.GODOY, I. J.; MINOTTI, D.; RESENDE, P. L. Produção de amendoim de qualidade. Viçosa: Centro de Produções Técnicas, 2005. $168 \mathrm{p}$.

MARTINS, R. Cultivares de amendoim: um estudo sobre as contribuições da pesquisa pública paulista. Informações Econômicas, São Paulo, v. 36, n. 5, p. 37-49, 2006.NAKAGAWA, J. et al. Efeito da densidade de semeadura na produção do amendoim. Pesquisa Agropecuária Brasileira, Brasília, v. 29, n. 10, p. 1547-1555, 1994.

OLIVEIRA, T.M.; QUEIROGA, R.C.; NOGUEIRA, F.P.; MOREIRA, J.N.; SANTOS, A.S; Produção de cultivares decumbentes de amendoim submetidas a distintos espaçamentos. Revista Caatinga, Mossoró, v. 23, n. 4, p. 149-154, out.-dez., 2010, Universidade Federal Rural do Semiárido, 2010.

ROMANINI JUNIOR, A. Influência do espaçamento de plantas no crescimento, produtividade e rendimento do amendoim rasteiro, cultivar Runner IAC 886, Dissertação (mestrado em agronomia - Produção Vegetal). Universidade Estadual Paulista, Faculdade de Ciências Agrárias e Veterinárias, 2007.

SILVA, M. B. da; BELTRÃO, N. E. de M. Níveis populacionais e configurações de plantio na cultura do amendoim, em regime de sequeiro na mesorregião do agreste da Borborema do estado da Paraíba. Revista Brasileira de Oleaginosas e Fibrosas, Campina Grande, v. 4, n. 1, p. 23-34, 2000.

TASSO JUNIOR, L. C.; MARQUES, M. O.; NOGUEIRA, G. A. A cultura do amendoim. Jaboticabal: Editora FUNEP, 2004. p. 1-220.

WALKER, E.R.; MENGISTU, A.; BELlALOUI, N.; KOGER, C.H.; ROBERTS, R.K.; LARSON, J.A. Plant population and row-spacing effects on maturity group III soybean. Agronomy Journal, Madison, v.102, n.3, p.821-826, 2010.

ZERBATO, C.; VOLTARELli M.A; COMPAGNON, A. M.; CASSIA, M.T.; SILVA, R. P. Controle de qualidade na semeadura de amendoim em espaçamento duplo, XLIII Congresso Brasileiro de Engenharia Agrícola - CONBEA, - Campo Grande-MS (Congresso) 2014. 